\title{
COVID-19 and sex workers: human rights, the struggle for safety and minimum income
}

\author{
Ehsan Jozaghi ${ }^{1,2}$ (D) Lorna Bird ${ }^{3,4,5,6}$
}

Received: 14 May 2020 / Accepted: 20 May 2020 / Published online: 2 June 2020

(C) The Canadian Public Health Association 2020

Dear Editors,

As the number of deaths around the world linked to COVID-19 surpasses 300,000, we are reminded once again of how marginalization and socio-economic status affect mortality rates at the micro and macro levels. For example, at the macro level, the latest cases from epidemiological studies indicate that poorer countries with a lower GDP could potentially have higher mortalities linked to COVID-19 (LloydSherlock et al. 2020). At the micro level, it has already been shown that racial minorities (e.g., Black communities) in the United States have higher rates of infection and death linked to COVID-19 (Laurencin and McClinton 2020). Similarly, in Canada, some have raised concerns about marginalized populations and their higher risk for COVID-19 cases (Jozaghi et al. 2020). We would like to raise concerns towards the risk of COVID-19 infection for sex workers and how the current state of legislation substantially increases this risk.

Bill C-36 (the Protection of Communities and Exploited Persons Act) was introduced by the Conservative federal government in 2014, shortly after the earlier decision by the Supreme Court of Canada that found Canada's

\section{Ehsan Jozaghi}

eja2@sfu.ca

1 The British Columbia Centre for Disease Control, 655 W 12th Ave, Vancouver, BC V5Z 4R4, Canada

2 The School of Population and Public Health, University of British Columbia, E Mall, 2206 E Mall, Vancouver, BC V6T 1Z33, Canada

3 Sex Workers United Against Violence Society, 334 Alexander St, Vancouver, BC V6A 1C3, Canada

4 PACE Society (Providing Advocacy Counselling \& Education), 148 W. Hastings St., Vancouver, BC V6B 1G8, Canada

5 The Western Aboriginal Harm Reduction Society, 380 E Hastings St, Vancouver, BC V6A 1P4, Canada

6 The Vancouver Area Network of Drug Users, 380 E Hastings St, Vancouver, BC V6A 1P4, Canada prostitution laws unconstitutional. Bill C-36 places sex workers at an increased risk of poor health and safety, as the law prohibits anyone to buy or advertise sexual services (Canada (AG) v Bedford 2013; Department of Justice 2014). This is particularly significant in the current pandemic, as many provinces have ordered massage parlours as well as saunas, spas or similar establishments to shut down (Orton 2020). At the same time, sex workers across Canada are increasingly worried for their personal health, as COVID-19 has caused the closure of many safe locations for work (Wyton 2020). COVID-19 concerns have simultaneously slashed demand, and sex workers' incomes have been impacted drastically (Wyton 2020).

This is particularly significant because sex workers do not qualify for employment insurance or many of the recent governments' emergency support and rent assistance for individuals, students, seniors, non-profits, small- and medium-sized businesses, sports and culture sectors (Fry 2020). Consequently, sex workers are further marginalized during the current pandemic and are forced to work in risky situations in order to survive and feed their families. For example, out of approximately 2600 sex workers in Vancouver, at least $20 \%$ are estimated to be involved in survival sex work, which means they rely on this work to pay for food, rent or the maintenance level of illegal drugs (Canadian Public Health Association 2014). We urge the federal and provincial governments to work with sex work advocacy and harm reduction organizations to provide financial support to sex workers. At the same time, we urge the federal government to amend Bill C-36. As the Chief Justice of the Supreme Court of Canada, Beverly McLachlin, pointed out, "Parliament has the power to regulate against nuisances, but not at the cost of the health, safety and lives of prostitutes" (Canada (AG) v Bedford 2013, para 11).

Acknowledgements Caimen Yen's editorial assistance is acknowledged on this letter. 


\section{References}

Canada (Attorney General) v. Bedford (2013). Supreme Court of Canada. 72 (CanLII), [2013] 3 SCR 1101, retrieved from: http://canlii.ca/t/ g2f56

Canadian Public Health Association (2014). Sex work in Canada: the public health perspective. Retrieved from: https://www.cpha.ca/ sites/default/files/assets/policy/sex-work_e.pdf.

Fry, H. (2020). Dr. Hedy Fry: Sex workers and COVID-19. The Georgia Straight. Retrieved from: https://www.straight.com/news/dr-hedyfry-sex-workers-and-covid-19.

Jozaghi, E., Maynard, R., Hamm, D., \& Marsh, S. (2020). COVID-19 and people who use drugs: a call for action. Canadian Journal of Public Health. https://doi.org/10.17269/s41997-020-00326-1.

Laurencin, C. T., \& McClinton, A. (2020). The COVID-19 pandemic: a call to action to identify and address racial and ethnic disparities. $J$ Racial Ethn Health Disparities, 1-5. https://doi.org/10.1007/ s40615-020-00756-0.
Lloyd-Sherlock, P., Ebrahim, S., Geffen, L., \& McKee, M. (2020). Bearing the brunt of covid-19: older people in low and middle income countries. The BMJ, 368. https://doi.org/10.1136/bmj.m1052.

Orton, T. (2020). B.C. orders all salons, parlours closed as 74 new COVID-19 cases reported. Pique Publishing. Retrieved from: https://www.piquenewsmagazine.com/whistler/bc-orders-allsalons-parlours-closed-as-74-new-covid-19-cases-reported/ Content?oid $=15192877$.

The Department of Justice (2014). Prostitution criminal law reform: Bill C-36, the Protection of Communities and Exploited Persons Act. Retrieved from: https://www.justice.gc.ca/eng/rp-pr/other-autre/ c36fs_fi $/$.

Wyton, M. (2020). How the COVID-19 crisis is hurting sex workers. The Tyee. Retrieved from: https://thetyee.ca/News/2020/03/27/HowCOVID-19-Hurting-Sex-Workers/.

Publisher's note Springer Nature remains neutral with regard to jurisdictional claims in published maps and institutional affiliations. 